\title{
Interleukin-2 is upregulated in patients with a prolapsed lumbar intervertebral disc and modulates cell proliferation, apoptosis and extracellular matrix metabolism of human nucleus pulposus cells
}

\author{
ZHIRONG WANG ${ }^{1,2^{*}}$, GENLIN WANG $^{1 *}$, XUESONG ZHU ${ }^{1}$, DECHUN GENG $^{1}$ and HUILIN YANG ${ }^{1}$ \\ ${ }^{1}$ Department of Orthopedic Surgery, The First Affiliated Hospital of Soochow University, Suzhou, Jiangsu 215006; \\ ${ }^{2}$ Department of Orthopedic Surgery, Zhangjiagang Hospital of Traditional Chinese Medicine, \\ Zhangjiagang, Jiangsu 215600, P.R. China
}

Received January 30, 2015; Accepted September 25, 2015

DOI: $10.3892 /$ etm.2015.2809

\begin{abstract}
Previous studies have demonstrated that the expression levels of cytokines are increased in degenerated intervertebral disc tissues, and several cytokines are associated with the pathogenesis of intervertebral disc degeneration. However, the role of interleukin (IL)-2 in the cellular functions of intervertebral disc tissues remains unreported. The present study aimed to determine the expression levels of IL-2 in the nucleus pulposus (NP) tissues of patients with a prolapsed lumbar intervertebral disc; and to observe the changes in cell proliferation, apoptosis, extracellular matrix (ECM) metabolism and p38 mitogen-activated protein kinase (MAPK) signaling in human NP cells (HNPCs) following treatment with IL-2. The present study demonstrated that IL-2 expression levels were upregulated in the NP tissues of patients with a prolapsed lumbar intervertebral disc; and a subsequent MTT assay demonstrated that IL-2 inhibits the proliferation of HNPCs in a dose-dependent manner. Furthermore, as demonstrated by the increased protein expression levels of Fas cell surface death receptor and the induction of caspase- 8 and caspase-3 activity, the death receptor pathway was activated by IL-2 in the HNPCs in order to promote cell apoptosis. In addition, IL-2 promoted ECM degradation in the HNPCs, as demonstrated by an increase in the expression levels of type I collagen, a disintegrin and metalloproteinase with thrombospondin motifs and matrix metalloproteinases, and decreased aggrecan and type II collagen expression levels. Furthermore, phosphorylated-p38 was significantly increased in the HNPCs
\end{abstract}

Correspondence to: Professor Huilin Yang, Department of Orthopedic Surgery, The First Affiliated Hospital of Soochow University, 188 Shizi Road, Suzhou, Jiangsu 215006, P.R. China

E-mail: hui_lin_yang@163.com

*Contributed equally

Key words: interleukin-2, nucleus pulposus cells, proliferation, apoptosis, extracellular matrix metabolism following IL-2 treatment. In conclusion, the present study demonstrated that IL-2 inhibits cell proliferation, and induces cell apoptosis and ECM degradation, accompanied by the activation of p38 MAPK signaling in HNPCs. Therefore, IL-2 may be a potential therapeutic agent for the treatment of degenerative disc disease.

\section{Introduction}

The prolapse of a lumbar intervertebral disc is a common ailment that places pressure on the surrounding nerves and causes pain in the waist and leg. Intervertebral disc degeneration (IDD) has been demonstrated to be the main cause of lumbar intervertebral disc prolapse. Approximately $20 \%$ of teenage indiciduals have discs with mild signs of degeneration, while $\sim 10 \%$ of 50 -year-old individuals and $\sim 60 \%$ of 70-year-old individuals posses discs that exhibit severe degeneration (1). However, the pathogenesis of IDD is associated with various cellular and biochemical alterations (2). IDD is associated with numerous risk factors, including lifestyle, co-morbidities, genetic predisposition and age (3).

Previous studies have detected high expression levels of cytokines in degenerated intervertebral disc tissues, including interleukin (IL)-1, interferon (IFN) $-\gamma$ and tumor necrosis factor (TNF)- $\alpha$, and these cytokines are associated with the pathogenesis of IDD (4-6).

IL-2, which is a pleiotropic cytokine primarily produced by $\mathrm{T}$ lymphocytes, has been implicated in the development and control of inflammatory disease $(7,8)$. A previous study demonstrated that IL-2 mRNA expression was downregulated in the epidural compartment following intervertebral disc extrusion (9), and IL-2 expression levels in the disc samples of patients with lumbar degenerative disc disease were significantly increased, as compared with the controls (10). These findings suggested that IL-2 may be associated with intervertebral disc disease; however, the role of IL-2 in the cellular functions of intervertebral disc tissues remains unclear.

In the present study, the expression levels of IL-2 in the nucleus pulposus (NP) tissues, the avascular and aneural tissues in the center of the intervertebral disc, of patients with prolapsed lumbar intervertebral discs were investigated, and in 
vitro experiments were performed in order to investigate the role of IL-2 in the proliferation of human NP cells (HNPCs), apoptosis and extracellular matrix (ECM) metabolism. In addition, alterations in p38 mitogen-activated protein kinase (MAPK) signaling were examined in the HNPCs, a potential target for treating IDD, following IL-2 treatment.

\section{Materials and methods}

Clinical samples. The present study was approved by the Ethics Committee of The First Affiliated Hospital of Soochow University (Suzhou, China). Informed consent was obtained from all patients prior to enrollment onto the present study. Human NP tissues were obtained from 30 patients undergoing surgery for prolapsed lumbar intervertebral discs, whereas control NP tissues were obtained from 10 patients undergoing surgery for spinal trauma. The 30 patients diagnosed with prolapsed lumbar intervertebral discs included 15 males and 15 females, and the mean age was 51 years. The 10 patients with spinal trauma included 4 males and 6 females, with a mean age of 49 years.

Cell culture and treatment. HNPCs were purchased from ScienCell Research Laboratories (Carlsbad, CA, USA) and cultured in NP Cell Medium (ScienCell Research Laboratories) in an atmosphere containing $5 \% \mathrm{CO}_{2}$ and $95 \%$ air. The NP Cell culture medium was changed every three days. IL-2 (Sigma-Aldrich, St. Louis, MO, USA) was dissolved in sterile distilled water, and the HNPCs were treated with 1, 5, 10 or $20 \mathrm{ng} / \mathrm{ml}$ IL-2.

Enzyme-linked immunosorbent assay (ELISA). IL-2 expression levels in the NP tissues were determined using an IL-2 ELISA kit (R\&D Systems, Inc., Minneapolis, MN, USA), according to the manufacturer's protocol. Briefly, the NP tissues were homogenized using a Dounce tissue grinder (Sigma-Aldrich) and centrifuged at $1,000 \mathrm{x} \mathrm{g}$ for $10 \mathrm{~min}$ at $4^{\circ} \mathrm{C}$, and $100 \mu \mathrm{l}$ of either standard, control (phosphate-buffered saline; PBS) or sample was subsequently pipetted into each well, and incubated with $100 \mu \mathrm{l}$ assay diluent for $2 \mathrm{~h}$ at room temperature. Following washing, $200 \mu$ l conjugate was added and incubated for $2 \mathrm{~h}$ at room temperature prior to the addition of $200 \mu \mathrm{l}$ substrate solution to develop the color. Reactions were terminated by adding $50 \mu \mathrm{l}$ Stop solution and the absorbance was measured at $450 \mathrm{~nm}$ using a Multiskan Spectrum spectrophotometer (Thermo Fisher Scientific, Inc., Waltham, MA, USA).

Cell viability 3-(4,5-dimethylthiazol-2-yl)-2,5-diphenyltetrazolium bromide (MTT) assay. Cell viability was measured using an MTT assay. The cells were seeded into 96-well plates and incubated with $1,5,10$ or $20 \mathrm{ng} / \mathrm{ml}$ IL-2 for $12,24,48$ and $72 \mathrm{~h}$, respectively. Following this, $0.5 \mathrm{mg} / \mathrm{ml} \mathrm{MTT}$ solution (Sigma-Aldrich, St. Louis, MO, USA) was added to each well, and the plates were incubated for $4 \mathrm{~h}$ at $37^{\circ} \mathrm{C}$. Subsequently, the medium was removed and $200 \mu$ l dimethyl sulfoxide (Invitrogen; Thermo Fisher Scientific Inc., Waltham, MA, USA) was subsequently added into each well. The absorbance was measured at $570 \mathrm{~nm}$ using a Multiskan Spectrum spectrophotometer (Thermo Fisher Scientific, Inc.).
Table I. Primer sequences for reverse transcription-quantitative polymerase chain reaction.

Name Primer sequences (5'-3')

IL-2 F: ACCTCAACTCCTGCCACAAT

Aggrecan R: TCCTGGTGAGTTTGGGATTC

Aggrecan
F: CTGCTTCCGAGGCATTTCAG

Type I collagen R: CTTGGGTCACGATCCACTCC

Type II collagen F: GGTCTTGGTGGAAACTTTGCT

F: GTCGAGGGCCAAGACGAAG R: CAGATCACGTCATCGCACAAC

ADAMTS-4 R: GGTCCTTGCATTACTCCCAAC

F: ACTGGTGGTGGCAGATGACA

ADAMTS-5 R: TCACTGTTAGCAGGTAGCGCTTT

MMP-3 F: GGACCTACCACGAAAGCAGATC

R: GCCGGGACACACGGAGTAC

MMP-13

F: TGAAGAGTCTTCCAATCCTACTGT TG R:CTAGATATTTCTGAACAAGGTTCATGCA

MMP-13 F: GGACAAGTAGTTCCAAAGGCTACA A

GAPDH R: CTTTTGCCGGTGTAGGTGTAGATAG F: CAATGACCCCTTCATTGACC R: GACAAGCTTCCCGTTCTCAG

F, forward; R, reverse; IL-2, interleukin-2; ADAMTS, a disintegrin and metalloproteinase with thrombospondin motifs; MMP, matrix metalloproteinase; GAPDH, glyceraldehyde-3-phosphate dehydrogenase. GAPDH was used as a housekeeping gene.

Analysis of caspase-3 and caspase- 8 activities. Caspase-3 and caspase- 8 activities in HNPCs were measured using a Caspase Activity kit (Beyotime Institute of Biotechnology, Shanghai, China), according to the manufacturer's protocol. Briefly, the cells were washed and lysed prior to incubation of the supernatant with acetyl-Asp-Glu-Val-Asp p-nitroanilide and N-Acetyl-Ile-Glu-Thr-Asp-p-nitroanilide, respectively. The release of p-nitroaniline was determined by measuring the absorbance at $405 \mathrm{~nm}$ using a SpectraMax 190 microplate reading (Molecular Devices, LLC, Sunnyvale, CA, USA). The caspase activities were expressed as a percentage, relative to the control.

Reverse transcription-quantitative polymerase chain reaction $(R T-q P C R)$. Tissues were homogenized using the Dounce tissue grinder. Total RNA was harvested from the NP tissues or the HNPCs using TRIzol ${ }^{\circledR}$ reagent (Invitrogen; Thermo Fisher Scientific Inc.), and subsequently reverse transcribed into cDNA using a First Strand cDNA Synthesis kit (Fermentas; Thermo Fisher Scientific Inc.), according to the manufacturer's instructions. The primers for RT-qPCR are outlined in Table I. PCR amplification was performed with 2 ng cDNA using a 7300 Sequence Detection system (Applied Biosystems; Thermo Fisher Scientific, Inc.) with a SYBR ${ }^{\circledR}$ Green PCR kit (Applied Biosystems; Thermo Fisher Scientific, Inc.). The cycling conditions were as follows: $5 \mathrm{~min}$ at $95^{\circ} \mathrm{C}$, followed by 42 cycles of $5 \mathrm{~min}$ at $95^{\circ} \mathrm{C}, 15 \mathrm{sec}$ at $58^{\circ} \mathrm{C}$ and $10 \mathrm{sec}$ at $72^{\circ} \mathrm{C}$, finally $10 \mathrm{~min}$ at $95^{\circ} \mathrm{C}$. Relative mRNA expression levels were calculated using the $2^{-\Delta \Delta \mathrm{Cq}}$ 
method (11). Data are presented as fold changes, normalized to the control.

Western blot analysis. Proteins were isolated using a Total Protein Extraction kit (Nanjing KeyGEN Biotech Inc., Nanjing, China). Protein concentrations were determined using a BCA Protein Assay Kit (C503021; Sangon Biotech Co., Ltd., Shanghai, China). Total proteins $(25 \mu \mathrm{g})$ were separated by $10 \%$ sodium dodecyl sulfate-polyacrylamide gel electrophoresis and transferred via electroblotting onto polyvinylidene difluoride membranes (EMD Millipore, Billerica, MA, USA). The membranes were blocked with $5 \%$ bovine serum albumin at $4^{\circ} \mathrm{C}$ overnight and subsequently incubated at $37^{\circ} \mathrm{C}$ for $1 \mathrm{~h}$ with the following primary antibodies: Mouse monoclonal antibodies to p38 MAPK (\#9217; 1:400), phosphorylated-p38 MAPK (\#9216; 1:200) and Fas cell surface death receptor (Fas; \#8023; 1:500; Cell Signaling Technology, Inc., Beverly, MA, USA); rabbit polyclonal antibody to matrix metalloproteinase (MMP)-13 (ab39012; 1:400); mouse monoclonal antibodies to collagen I (ab90395; 1:500), collagen II (ab185430; 1:500) and MMP-3 (ab17790; 1:400) Abcam, Cambridge, UK); rabbit polyclonal antibodies to a disintegrin and metalloproteinase with thrombospondin motifs (ADAMTS)-4 (sc-25582; 1:800) and ADAMTS-5 (sc-83186; 1:400); and mouse monoclonal antibodies to aggrecan and glyceraldehyde 3-phosphate dehydrogenase (GAPDH; sc-365062; 1:1,000; Santa Cruz Biotechnology, Inc., Dallas, TX, USA). GAPDH was used as a housekeeping gene. Following this, the membranes were washed with PBS and incubated with a horseradish peroxidase-labeled goat anti-rabbit IgG/HRP (sc-2004; 1:5,000) and goat anti-mouse IgG/HRP (sc-2031; 1:5,000; Santa Cruz Biotechnology, Inc.) secondary antibody at $37^{\circ} \mathrm{C}$ for $1 \mathrm{~h}$. Immunolabeling was detected using an enhanced chemiluminescence reagent and a Western Blotting kit (Pierce Biotechnology, Inc., Rockford, IL, USA). The blots were analyzed using Image-Pro Plus software (Media Cybernetics, Inc., Rockville, MD, USA)

Statistical analysis. Data were analyzed using SPSS 19.0 statistical software (IBM SPSS, Armonk, NY, USA) and presented as the mean \pm standard deviation. Statistical differences between the two groups were analyzed using a Student's t-test. $\mathrm{P}<0.05$ was considered to indicate a statistically significant difference.

\section{Results}

IL-2 expression levels are increased in patients with a prolapsed lumbar intervertebral disc. In order to determine the expression levels of IL-2 in the NP tissues, NP tissues were collected from the patients and controls as outlined, prior to RT-qPCR and ELISA analyses. IL-2 mRNA expression levels were significantly increased in the NP tissues of patients with a prolapsed lumbar intervertebral disc, as compared with the controls $(\mathrm{P}<0.01$; Fig. 1). Furthermore, IL-2 protein expression levels were significantly increased in the NP tissues of patients with a prolapsed lumbar intervertebral disc $(\mathrm{P}<0.05$; Fig. 2).

IL-2 inhibits the proliferation of HNPCs in a dose-dependent manner. To investigate the effects of IL-2 on the proliferation

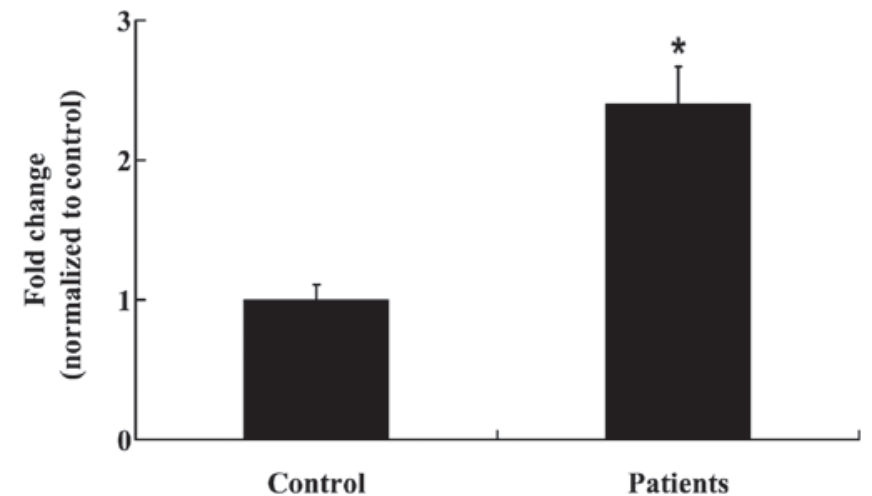

Figure 1. Interleukin-2 mRNA expression levels in the nucleus pulposus of patients with a prolapsed lumbar intervertebral disc and controls. Data are presented as the mean \pm standard deviation. ${ }^{*} \mathrm{P}<0.01$ vs. the controls.

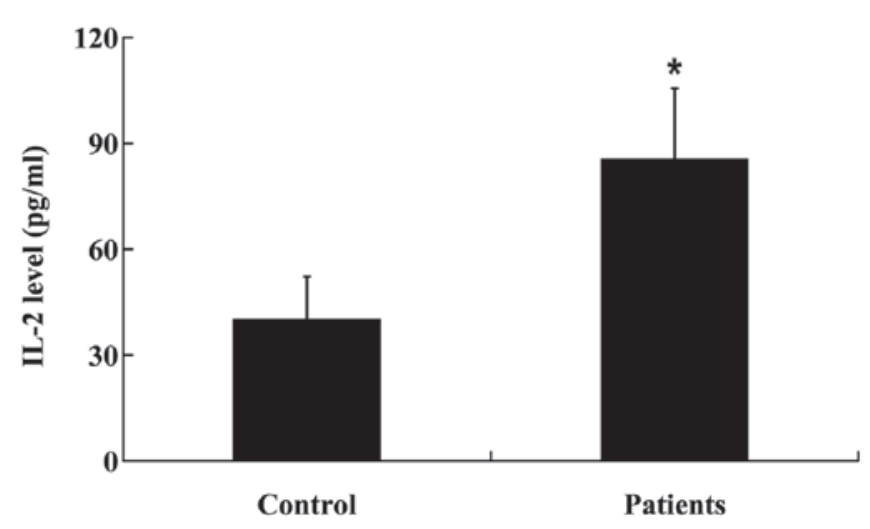

Figure 2. Interleukin (IL)-2 protein expression levels in the nucleus pulposus of patients with a prolapsed lumbar intevertebral disc and controls. Data are presented as the mean \pm standard deviation. ${ }^{*} \mathrm{P}<0.05$ vs. control.

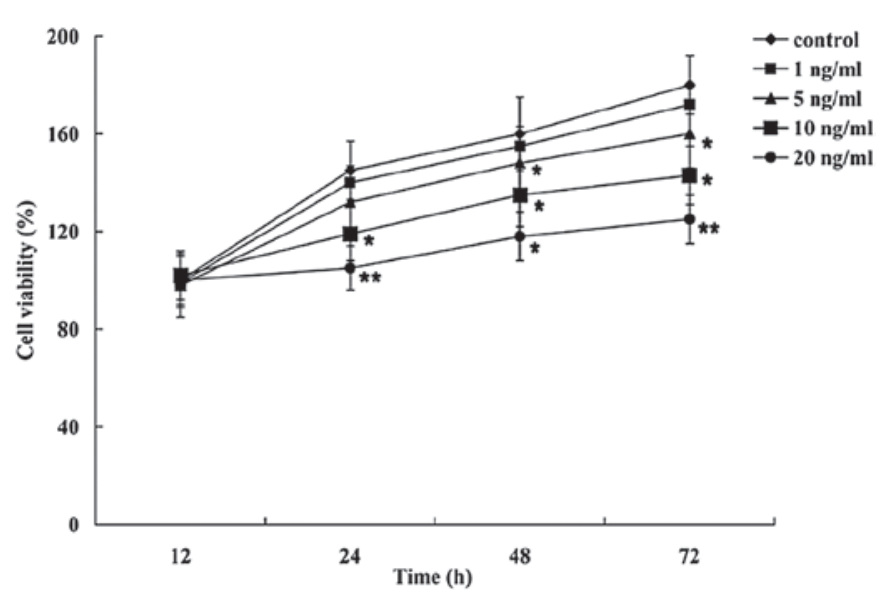

Figure 3. Cell viability of human nucleus pulposus cells following treatment with various concentrations $(1,5,10$ and $20 \mathrm{ng} / \mathrm{ml})$ of interleukin-2. Data are presented as the mean \pm standard deviation. ${ }^{*} \mathrm{P}<0.05$ and ${ }^{* *} \mathrm{P}<0.01$ vs. control.

of HNPCs, the cells were treated with various concentration of IL-2 (1, 5, 10 and $20 \mathrm{ng} / \mathrm{ml})$, and an MTT assay was performed. As demonstrated in Fig. 3, IL-2 inhibited the proliferation of the HNPCs in a dose-dependent manner. No significant effects on the viability of the HNPCs were observed at the lowest IL-2 concentration (1 ng/ml); however, 


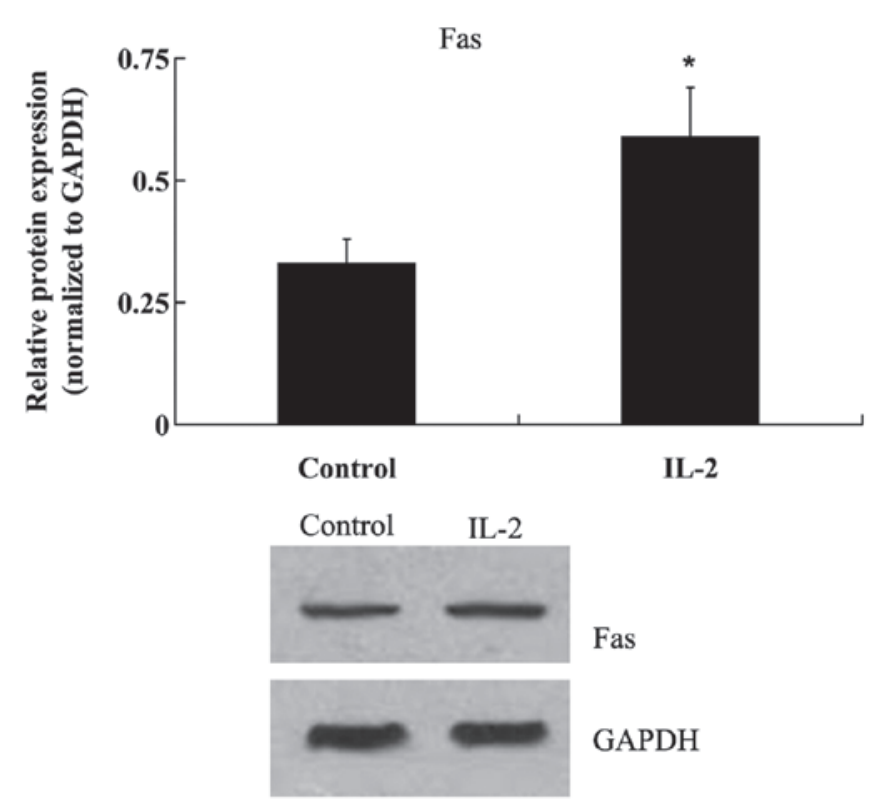

Figure 4. Protein expression levels of Fas cell surface death receptor (Fas) in human nucleus pulposus cells following treatment with interleukin (IL)-2. Glyceraldehyde-3-phosphate dehydrogenase (GAPDH) was used as a housekeeping gene. Data are presented as the mean \pm standard deviation. ${ }^{*} \mathrm{P}<0.05$ vs. the control.
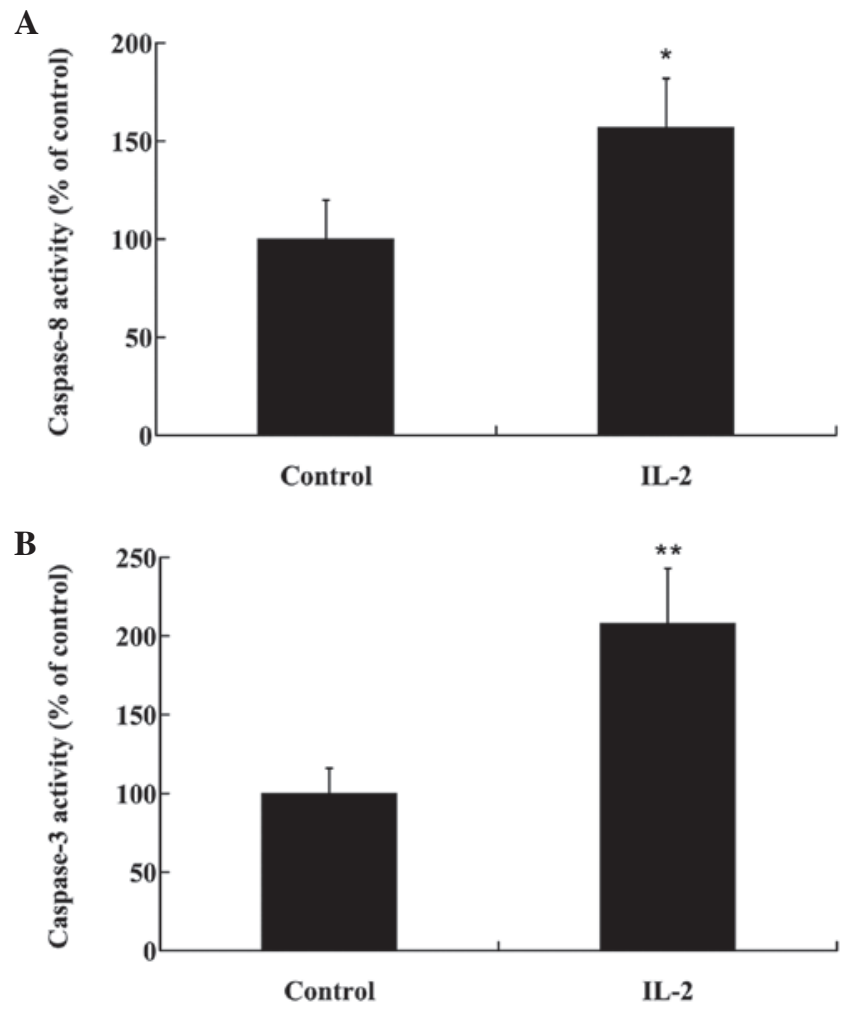

Figure 5. Activity of (A) caspase- 8 and (B) caspase-3 in human nucleus pulposus cells following treatment with interleukin (IL)-2. Data are presented as the mean \pm standard deviation. ${ }^{*} \mathrm{P}<0.05$ and $^{* *} \mathrm{P}<0.01$ vs. the control.

5, 10 and $20 \mathrm{ng} / \mathrm{ml} \mathrm{IL-2} \mathrm{significantly} \mathrm{decreased} \mathrm{the} \mathrm{viability}$ of the HNPCs.

IL-2 significantly increases the expression levels of apoptosis-related proteins in HNPCs. To investigate the effects of
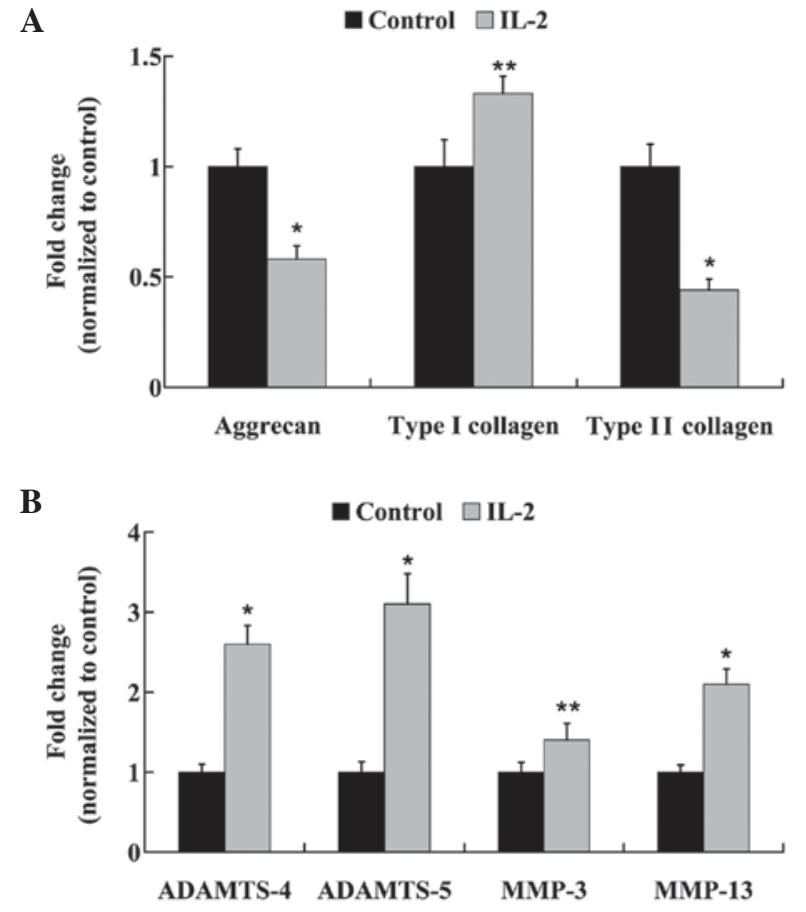

Figure 6. mRNA expression levels of (A) aggrecan, type I and II collagen, and (B) a disintegrin and metalloproteinase with thrombospondin motifs (ADAMTS)-4, ADAMTS-5, matrix metalloproteinase (MMP)-3 and MMP-13 in human nucleus pulposus cells following treatment with interleukin (IL)-2. Data are presented as the mean \pm standard deviation. " $\mathrm{P}<0.01$ and ${ }^{* *} \mathrm{P}<0.05$ vs. the control.

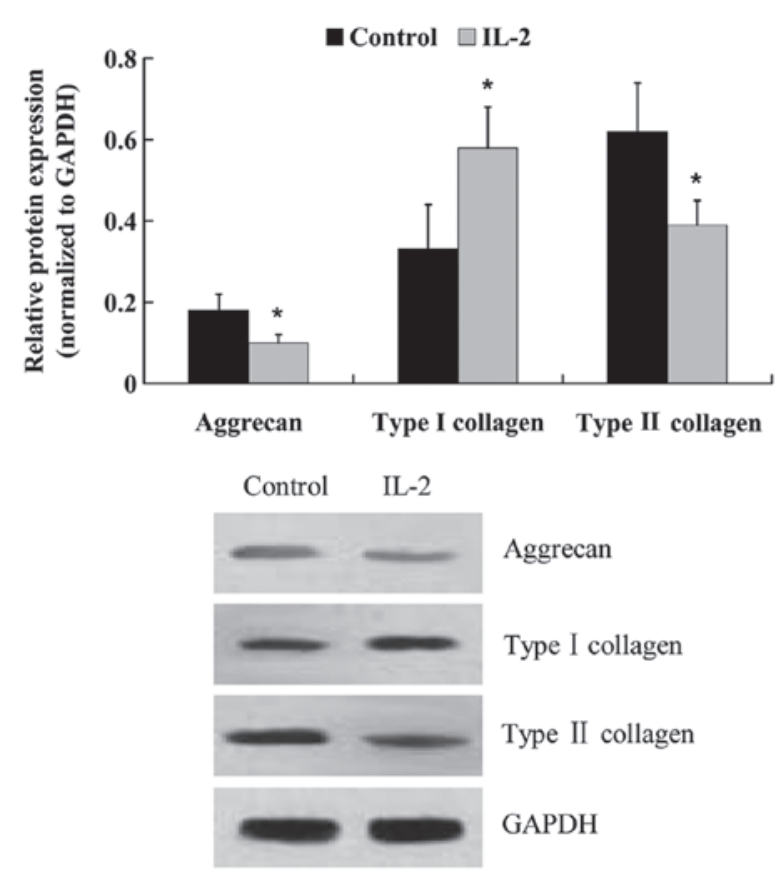

Figure 7. Protein expression levels of aggrecan, and type I and II collagen in the human nucleus pulposus cells following treatment with interleukin (IL)-2. Glyceraldehyde-3-phosphate dehydrogenase (GAPDH) was used as a housekeeping gene. Data are presented as the mean \pm standard deviation. ${ }^{*} \mathrm{P}<0.05$ vs. the control.

IL-2 on the apoptosis of HNPCs, the cells were treated with $20 \mathrm{ng} / \mathrm{ml} \mathrm{IL}-2$ for $24 \mathrm{~h}$. Fas protein expression levels were analyzed by western blot analysis, and the activities of caspase- 3 
and -8 were analyzed in the HNPCs, using commercial kits. As demonstrated in Fig. 4, IL-2 significantly increased $(\mathrm{P}<0.05)$ the protein expression levels of Fas in the HNPCs; and the activities of caspase- 3 and -8 were also increased in the HPNCs following treatment with IL-2 (Fig. 5A and B)

IL-2 affects ECM metabolism in HNPCs. HNPCs were treated with $20 \mathrm{ng} / \mathrm{ml} \mathrm{IL-2} \mathrm{for} 24 \mathrm{~h}$, and the mRNA expression levels of: Aggrecan; type I and type II collagen; ADAMTS-4 and -5; and MMP-3 and -13 were analyzed using RT-qPCR. As outlined in Fig. 6A, the mRNA expression levels of aggrecan were reduced by $58 \%$ following treatment with IL-2 in the HNPCs. Furthermore, following IL-2 administration, a 1.33-fold increase in the mRNA expression levels of type I collagen was detected; however, type II collagen mRNA expression levels were significantly decreased $(\mathrm{P}<0.05)$. Furthermore, IL-2 treatment significantly increased $(\mathrm{P}<0.05)$ the mRNA expression levels of ADAMTS-4 and -5 , and MMP-3 and -13 (Fig. 6B).

The protein expression levels of: Aggrecan; type I and type II collagen; ADAMTS-4 and -5; and MMP-3 and -13 were examined by western blot analysis. Similar to the mRNA expression level results, IL-2 significantly increased $(\mathrm{P}<0.05)$ the protein expression levels of type I collagen, ADAMTS-4 and -5, MMP-3 and -13, whereas the protein expression levels of aggrecan and type II collagen were decreased (Fig. 7 and 8).

IL-2 induces the phosphorylation of p38 in HNPCs. The expression levels of $\mathrm{p} 38$ and its phosphorylated form were examined in the HNPCs following treatment with IL-2. As outlined in Fig. 9, the protein expression levels of p38 were not altered in response to IL-2 treatment; however, IL-2 successfully induced the phosphorylation of p38 in the HNPCs. The expression of phosphorylated-p38 protein was significantly upregulated in IL-2-treated HNPCs, as compared with the untreated control cells $(\mathrm{P}<0.05)$.

\section{Discussion}

The intervertebral disc contains a central NP encapsulated by endplates and the annulus fibrosus (12). The NP is an avascular and aneural tissue capable of resisting compressive loads, which acts as a pump in order to regulate the flow of liquids and gases in the disc. Therefore, the NP has a significant influence on the overall function and homeostasis of the intervertebral disc (13). In the present study, human NP tissues from patients presenting with a prolapsed lumbar intervertebral disc were harvested and the mRNA and protein expression levels of IL-2 were analyzed. The results demonstrated that IL-2 was highly upregulated in the NP tissues of patients with a prolapsed lumbar intervertebral disc, as compared with the control patients. These results suggested that IL- 2 may have a pathogenic role in the prolapse of lumbar intervertebral discs.

Previous studies have demonstrated that the expression levels of cytokines, including IL-1, IL-17 and TNF- $\alpha$, are elevated in pathological disc tissue, and they increase in line with the grade of degeneration $(6,14)$. These cytokines interact with a large genetic program that is instrumental in maintaining the appropriate homeostasis of cells within the intervertebral disc. A previous in vivo study demonstrated that

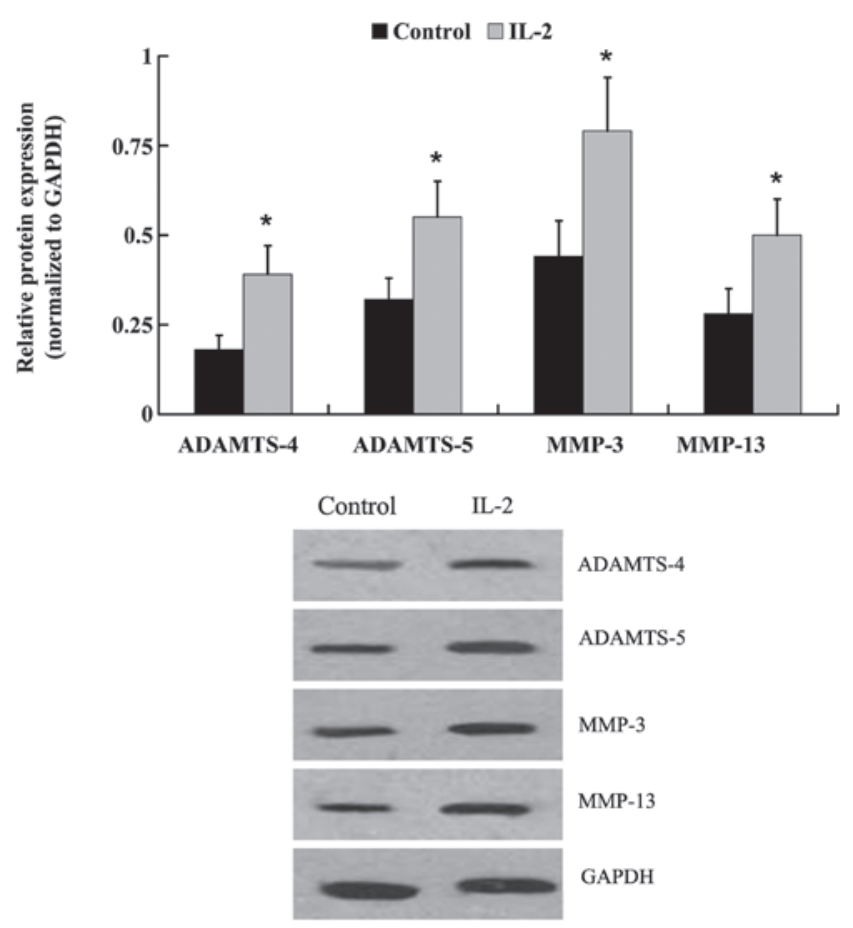

Figure 8. Protein expression levels of a disintegrin and metalloproteinase with thrombospondin motifs (ADAMTS)-4, ADAMTS-5, matrix metalloproteinase (MMP)-3 and MMP-13 in human nucleus pulposus cells following treatment with interleukin (IL)-2. Data are presented as the mean \pm standard deviation. ${ }^{*}<0.05$ vs. the control. Glyceraldehyde-3-phosphate dehydrogenase (GAPDH) was used as a housekeeping gene.
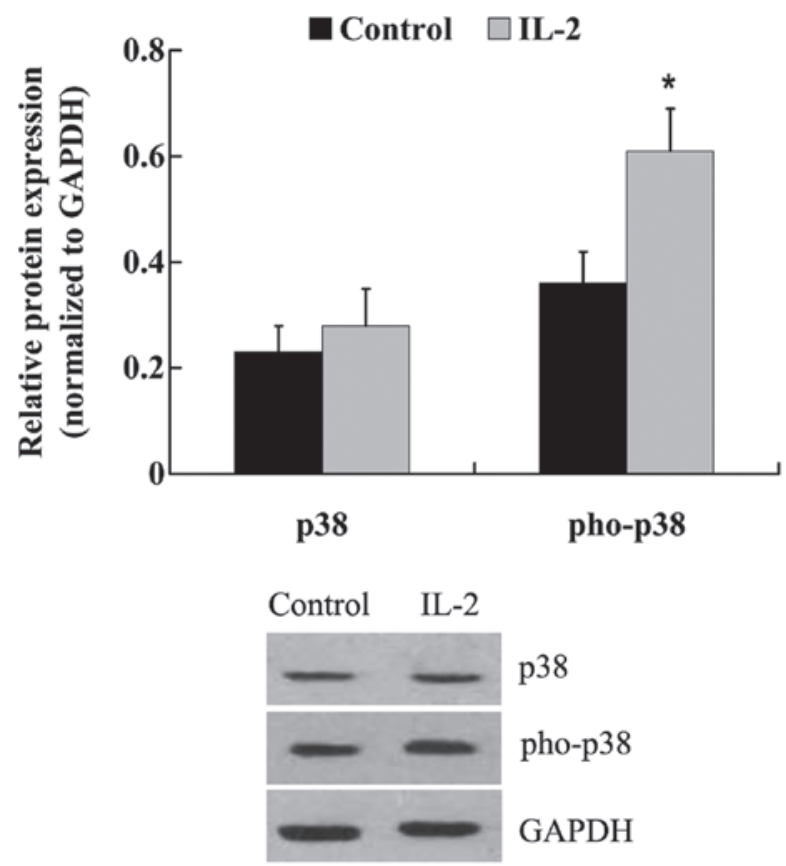

Figure 9. Protein expression levels of p38 and phophorylated (pho)-p38 in human nucleus pulposus cells following treatment with interleukin (IL)-2 . Glyceraldehyde-3-phosphate dehydrogenase (GAPDH) was used as a housekeeping gene. Data are presented as the mean \pm standard deviation. ${ }^{*} \mathrm{P}<0.05$ vs. the control.

IL-2 is upregulated in patients with a prolapsed lumbar intervertebral disc (4); however, the mechanisms underlying the association between IL-2 and IDD have yet to be elucidated. 
In the present study, in order to further understand the role of IL-2 in the pathophysiological mechanisms associated with disc degeneration, in vitro experiments were performed to determine the effects of IL-2 on apoptosis, ECM metabolism and the proliferation of HNPCs.

In the present study, the HNPCs were cultured and treated with various concentrations of IL-2. An MTT assay demonstrated that IL-2 inhibits the proliferation of HNPCs in a dose-dependent manner, and $20 \mathrm{ng} / \mathrm{ml} \mathrm{IL-2} \mathrm{was} \mathrm{determined}$ to be the optimal concentration for the inhibition of HNPCs. Furthermore, $20 \mathrm{ng} / \mathrm{ml}$ IL-2 was applied to investigate the effect of IL-2 on the apoptosis and ECM metabolism of HNPCs.

The NP of the intervertebral disc contains a proteoglycan-rich ECM, which normally functions to retain water $(15,16)$; however, degenerated intervertebral discs lose their normal architecture, leading to alterations in cell shape and biochemical characteristics. The role of apoptosis and apoptosis-related genes in the development of degenerative diseases has garnered much attention in recent years. The excessive apoptosis of NP cells, which are capable of producing ECM components, is one of the most discernable cellular and biochemical changes credited to degeneration (17-22). A previous study demonstrated that NP cells predominantly undergo apoptosis via the death receptor pathway, which contributes to degeneration of the intervertebral disc (23). The death receptor pathway is initiated by the binding of cell surface receptors, such as Fas, which activates initiator caspases, primarily caspase- 8 , which in turn activate effector caspases, predominantly caspase-3 (24). In the present study, IL-2 induced the expression of Fas protein and increased the activities of caspase- 3 and -8 in the HNPCs, thus suggesting that the death receptor pathway may be activated by IL-2 in HNPCs in order to promote cell apoptosis.

NP cells secrete a complex ECM comprised mainly of type II collagen and proteoglycans (25). Disc degeneration results from an imbalance between the degradation and synthesis of ECM components. Alterations in collagen type, and a decrease in proteoglycan content may cause dehydration and desiccation within the NP, and the intervertebral disc may become a more fibrotic and less cartilaginous structure (26-29) as a result. Aggrecan is a large proteoglycan that forms aggregates, the loss of which is considered to be an early biochemical abnormality of IDD (30). Previous studies have demonstrated that destructive enzymes, such as MMPs or ADAMTS, are upregulated in NP cells, leading to the downregulation of aggrecan and collagen type II (31-35). In order to elucidate the effects of IL-2 on ECM metabolism in the HNPCs, the expression levels of degrading enzymes that have been demonstrated to hydrolyze aggrecan and collagen were measured. RT-qPCR and western blot analysis demonstrated that the expression levels of ADAMTS-4 and -5, and MMP-3 and -13 were significantly increased following treatment with IL-2. In addition, aggrecan expression levels were significantly decreased, and collagen was altered from type II to I. These findings suggested that IL-2 may promote ECM degradation in HNPCs.

Studer et al (36) demonstrated that the p38 MAPK signaling pathway is a potential target for the treatment of IDD. NP cells respond to inflammatory cytokines via p38 MAPK; therefore, inhibition of p38 MAPK signaling may decrease the factors that negatively affect the metabolic balance and viability of NP cells. In the present study, phosphorylated-p38 was significantly upregulated following IL-2 treatment, suggesting that IL-2 may activate p38 MAPK signaling in HNPCs.

In conclusion, the expression of IL-2 was significantly upregulated in the NP tissues of patients with a prolapsed lumbar intervertebral disc. In addition, the present study demonstrated that IL-2 inhibits cell proliferation, induces cell apoptosis and ECM degradation, and activates p38 MAPK signaling in HNPCs. These findings provide a novel insight into the molecular pathogenesis of IDD.

\section{References}

1. Miller JA, Schmatz C and Schultz AB: Lumbar disc degeneration: Correlation with age, sex, and spine level in 600 autopsy specimens. Spine (Phila Pa 1976) 13: 173-178, 1988.

2. Smith LJ, Nerurkar NL, Choi KS, Harfe BD and Elliott DM: Degeneration and regeneration of the intervertebral disc: Lessons from development. Dis Model Mech 4: 31-41, 2011.

3. Adams MA and Roughley PJ: What is intervertebral disc degeneration, and what causes it? Spine (Phila Pa 1976) 31: 2151-2161, 2006.

4. Risbud MV and Shapiro IM: Role of cytokines in intervertebral disc degeneration: Pain and disc content. Nat Rev Rheumatol 10: 44-56, 2014.

5. Wang J, Markova D, Anderson DG, Zheng Z, Shapiro IM and Risbud MV: TNF- $\alpha$ and IL- $1 \beta$ promote a disintegrin-like and metalloprotease with thrombospondin type I motif-5-mediated aggrecan degradation through syndecan-4 in intervertebral disc. J Biol Chem 286: 39738-39749, 2011.

6. Shamji MF, Setton LA, Jarvis W, So S, Chen J, Jing L, Bullock R, Isaacs RE, Brown $\mathrm{C}$ and Richardson WJ: Proinflammatory cytokine expression profile in degenerated and herniated human intervertebral disc tissues. Arthritis Rheum 62: 1974-1982, 2010.

7. Kołodziejska-Sawerska A, Rychlik A, Depta A, Wdowiak M, Nowicki M and Kander M: Cytokines in canine inflammatory bowel disease. Pol J Vet Sci 16: 165-171, 2013.

8. Shachar I and Karin N: The dual roles of inflammatory cytokines and chemokines in the regulation of autoimmune diseases and their clinical implications. J Leukoc Biol 93: 51-61, 2013.

9. Karli P, Martlé V, Bossens K, Summerfield A, Doherr MG, Turner P, Vandevelde M, Forterre F and Henke D: Dominance of chemokine ligand 2 and matrix metalloproteinase-2 and -9 and suppression of pro-inflammatory cytokines in the epidural compartment after intervertebral disc extrusion in a canine model. Spine J 14: 2976-2984, 2014.

10. Akyol S, Eraslan BS, Etyemez H, Tanriverdi T and Hanci M: Catabolic cytokine expressions in patients with degenerative disc disease. Turk Neurosurg 20: 492-499, 2010.

11. Livak KJ and Schmittgen TD: Analysis of relative gene expression data using real-time quantitative PCR and the 2(-Delta Delta C(T)) Method. Methods 25: 402-408, 2001.

12. Minogue BM, Richardson SM, Zeef LA, Freemont AJ and Hoyland JA: Characterization of the human nucleus pulposus cell phenotype and evaluation of novel marker gene expression to define adult stem cell differentiation. Arthritis Rheum 62: 3695-3705, 2010

13. McCann MR, Bacher CA and Séguin CA: Exploiting notochord cells for stem cell-based regeneration of the intervertebral disc. J Cell Commun Signal 5: 39-43, 2011.

14. Le Maitre CL, Hoyland JA and Freemont AJ: Catabolic cytokine expression in degenerate and herniated human intervertebral discs: IL-1beta and TNFalpha expression profile. Arthritis Res Ther 9: R77, 2007.

15. Deyo RA and Tsui-Wu YJ: Descriptive epidemiology of low-back pain and its related medical care in the United States. Spine (Phila Pa 1976) 12: 264-268, 1987

16. Buckwalter JA: Aging and degeneration of the human intervertebral disc. Spine (Phila Pa 1976) 20: 1307-1314, 1995.

17. Chen JW, Ni BB, Li B, Yang YH, Jiang SD and Jiang LS: The responses of autophagy and apoptosis to oxidative stress in nucleus pulposus cells: Implications for disc degeneration. Cell Physiol Biochem 34: 1175-1189, 2014. 
18. Gruber HE and Hanley EN Jr: Biologic strategies for the therapy of intervertebral disc degeneration. Expert Opin Biol Ther 3: 1209-1214, 2003.

19. Zhao CQ, Jiang LS and Dai LY: Programmed cell death in intervertebral disc degeneration. Apoptosis 11: 2079-2088, 2006.

20. Zhao CQ, Wang LM, Jiang LS and Dai LY: The cell biology of intervertebral disc aging and degeneration. Ageing Res Rev 6: 247-261, 2007.

21. Chen YF, Zhang YZ, Zhang WL, Luan GN, Liu ZH, Gao Y, Wan ZY, Sun Z, Zhu S, Samartzis D et al: Insights into the hallmarks of human nucleus pulposus cells with particular reference to cell viability, phagocytic potential and long process formation. Int J Med Sci 10: 1805-1816, 2013

22. Jiang L, Zhang $X$, Zheng $X$, Ru A, Ni X, Wu Y, Tian N, Huang Y, Xue E, Wang X and Xu H: Apoptosis, senescence, and autophagy in rat nucleus pulposus cells: Implications for diabetic intervertebral disc degeneration. J Orthop Res 31: 692-702, 2013

23. Zeng S, Liu L and Wang J: Significance of BNIP3 gene expression and cell apoptosis in nucleus pulposus of degenerative intervertebral disc in rabbits. Zhongguo Xiu Fu Chong Jian Wai Ke Za Zhi 24: 1367-1371, 2010 (In Chinese).

24. Yurube T, Hirata H, Kakutani K, Maeno K, Takada T, Zhang Z, Takayama K, Matsushita T, Kuroda R, Kurosaka M and Nishida $K$ : Notochordal cell disappearance and modes of apoptotic cell death in a rat tail static compression-induced disc degeneration model. Arthritis Res Ther 16: R31, 2014.

25. Erwin WM and Hood KE: The cellular and molecular biology of the intervertebral disc: A clinician's primer. J Can Chiropr Assoc 58: 246-257, 2014.

26. Sivan SS, Hayes AJ, Wachtel E, Caterson B, Merkher Y, Maroudas A, Brown S and Roberts S: Biochemical composition and turnover of the extracellular matrix of the normal and degenerate intervertebral disc. Eur Spine J 23 (Suppl 3): S344-S353, 2014.
27. Antoniou J, Demers CN, Beaudoin G, Goswami T, Mwale F, Aebi M and Alini M: Apparent diffusion coefficient of intervertebral discs related to matrix composition and integrity. Magn Reson Imaging 22: 963-972, 2004.

28. Antoniou J, Steffen T, Nelson F, Winterbottom N, Hollander AP Poole RA, Aebi M and Alini M: The human lumbar intervertebral disc: Evidence for changes in the biosynthesis and denaturation of the extracellular matrix with growth, maturation, ageing, and degeneration. J Clin Invest 98: 996-1003, 1996.

29. Pritzker KP: Aging and degeneration in the lumbar intervertebral disc. Orthop Clin North Am 8: 66-77, 1977.

30. Pockert AJ, Richardson SM, Le Maitre CL, Lyon M, Deakin JA, Buttle DJ, Freemont AJ and Hoyland JA: Modified expression of the ADAMTS enzymes and tissue inhibitor of metalloproteinases 3 during human intervertebral disc degeneration. Arthritis Rheum 60: 482-491, 2009.

31. Arana CJ, Diamandis EP and Kandel RA: Cartilage tissue enhances proteoglycan retention by nucleus pulposus cells in vitro. Arthritis Rheum 62: 3395-3403, 2010.

32. Hamilton DJ, Pilliar RM, Waldman S and Kandel RA: Effect of circumferential constraint on nucleus pulposus tissue in vitro. Spine J 10: 174-183, 2010.

33. Le Maitre CL, Freemont AJ and Hoyland JA: Human disc degeneration is associated with increased MMP 7 expression. Biotech Histochem 81: 125-131, 2006.

34. Le Maitre CL, Pockert A, Buttle DJ, Freemont AJ and Hoyland JA: Matrix synthesis and degradation in human intervertebral disc degeneration. Biochem Soc Trans 35: 652-655, 2007.

35. MacLean JJ, Roughley PJ, Monsey RD, Alini M and Iatridis JC: In vivo intervertebral disc remodeling: Kinetics of mRNA expression in response to a single loading event. J Orthop Res 26: 579-588, 2008

36. Studer RK, Aboka AM, Gilbertson LG, Georgescu H, Sowa G, Vo N and Kang JD: p38 MAPK inhibition in nucleus pulposus cells: A potential target for treating intervertebral disc degeneration. Spine (Phila Pa 1976) 32: 2827-2833, 2007. 